\title{
Impaired Orthotopic Glioma Growth and Vascularization in Transgenic Mouse Models of Alzheimer's Disease
}

\author{
Daniel Paris, ${ }^{1}$ Nowel Ganey, ${ }^{1}$ Magdalena Banasiak, ${ }^{2}$ Vincent Laporte, ${ }^{1}$ Nikunj Patel, ${ }^{1}$ Myles Mullan, ${ }^{1}$ Susan F. Murphy, ${ }^{2}$ \\ Gi-Taek Yee, ${ }^{2}$ Corbin Bachmeier, ${ }^{1}$ Christopher Ganey, ${ }^{1}$ David Beaulieu-Abdelahad, ${ }^{1}$ Venkatarajan S. Mathura, ${ }^{1}$ \\ Steven Brem, ${ }^{2}$ and Michael Mullan ${ }^{1}$ \\ ${ }^{1}$ The Roskamp Institute, Sarasota, Florida 34243, and ${ }^{2} \mathrm{H}$. Lee Moffitt Cancer Center and Research Institute, Brain Tumor Research Laboratory, Tampa, \\ Florida 33612
}

\begin{abstract}
Alzheimer's disease (AD) is the most common form of dementia among the aging population and is characterized pathologically by the progressive intracerebral accumulation of $\beta$-amyloid $(\mathrm{A} \beta)$ peptides and neurofibrillary tangles. The level of proangiogenic growth factors and inflammatory mediators with proangiogenic activity is known to be elevated in AD brains which has led to the supposition that the cerebrovasculature of $\mathrm{AD}$ patients is in a proangiogenic state. However, angiogenesis depends on the balance between proangiogenic and antiangiogenic factors and the brains of $\mathrm{AD}$ patients also show an accumulation of endostatin and $\mathrm{A} \beta$ peptides which have been shown to be antiangiogenic. To determine whether angiogenesis is compromised in the brains of two transgenic mouse models of AD overproducing A $\beta$ peptides (Tg APPsw and Tg PS1/APPsw mice), we assessed the growth and vascularization of orthotopically implanted murine gliomas since they require a high degree of angiogenesis to sustain their growth. Our data reveal that intracranial tumor growth and angiogenesis is significantly reduced in Tg APPsw and Tg PS1/APPsw mice compared with their wild-type littermates. In addition, we show that $\mathrm{A} \beta$ inhibits the angiogenesis stimulated by glioma cells when cocultured with human brain microvascular cells on a Matrigel layer. Altogether our data suggest that the brain of transgenic mouse models of AD does not constitute a favorable environment to support neoangiogenesis and may explain why vascular insults synergistically precipitate the cognitive presentation of AD.
\end{abstract}

\section{Introduction}

Alzheimer's disease $(\mathrm{AD})$ is an ever-increasing health concern among the aging population. While the cause of the disease is uncertain, there are two major neuropathological hallmarks present in the brains of $\mathrm{AD}$ patients: the extracellular senile plaques containing a core of $\beta$-amyloid $(\mathrm{A} \beta)$ peptide and the intracellular neurofibrillary tangles made of hyperphosphorylated microtubule-associated protein tau. The progressive accumulation of $\mathrm{A} \beta$ in the brain is believed to produce the clinical phenotype of $\mathrm{AD}$ and, moreover, soluble $\mathrm{A} \beta$ rather than deposited/fibrillar $\mathrm{A} \beta$ is associated with dementia (Selkoe, 2008). The events that lead to the pathological accumulation of $\mathrm{A} \beta$ peptides in $\mathrm{AD}$ are the subject of active investigations. There is evidence that alterations in $\mathrm{A} \beta$ clearance across the blood brain barrier (BBB) plays a major role in brain $\mathrm{A} \beta$ accumulation (Zlokovic et al., 2000; Bell and Zlokovic, 2009). Other functional cerebrovascular alterations have been observed in $\mathrm{AD}$ and in transgenic mouse models of the disorder. In particular, cerebrovascular blood flow $(\mathrm{CBF})$ disturbances that reproduce some of the $\mathrm{CBF}$ alteration observed in $\mathrm{AD}$ patients have been well characterized

Received May 20, 2010; revised June 23, 2010; accepted June 30, 2010.

This work was supported by National Institutes of Health Grant R01A619250. We thank Diane and Robert Roskamp for their generosity in helping to make this work possible. We are grateful to Dr. David Zagzag from New York University School of Medicine for providing GL261 cells.

Correspondence should be addressed to Daniel Paris, The Roskamp Institute, 2040 Whitfield Avenue, Sarasota, FL 34243. E-mail:dparis@rfdn.org.

D0I:10.1523/JNEUROSCI.2586-10.2010

Copyright $\odot 2010$ the authors $\quad 0270-6474 / 10 / 3011251-08 \$ 15.00 / 0$ in transgenic mouse models of $\mathrm{AD}$ overexpressing $\mathrm{A} \beta$ (Iadecola, 2004). Interestingly, dysregulation of serum response factor and myocardin has been described in $\mathrm{AD}$ brain vascular cells and may initiate a pathogenic cascade resulting in hypercontractility of cerebral arterioles, CBF reduction (Chow et al., 2007) and decreased $\mathrm{A} \beta$ clearance across the $\mathrm{BBB}$, consequently facilitating the pathological accumulation of $A \beta$ and the progression of $A D$ (Bell et al., 2009).

Clearly, increasing evidence points to vascular damage as an early contributor to AD. Vascular pathologies synergistically exacerbate the cognitive presentation of AD (Snowdon et al., 1997) which is reflected in that fact that $\mathrm{AD}$ patients with cerebrovascular disease express the clinical symptoms of dementia with fewer AD pathological changes (Petrovitch et al., 2000; Hoffman et al., 2009). Considerable epidemiological evidence suggests that cardiovascular risk factors increase the risk of AD (Skoog et al., 1996). Numerous structural and functional cerebromicrovascular abnormalities have also been identified in AD subjects, including decreased microvessel density (Buée et al., 1997; Fischer et al., 1997; Perry et al., 1998; Suter et al., 2002; Bouras et al., 2006; Kitaguchi et al., 2007) and reduced expression of MEOX2 has been observed in $\mathrm{AD}$ brain endothelial cells resulting in aberrant angiogenic responses to angiogenic growth factors (Wu et al., 2005).

In $\mathrm{AD}$ brains, the levels of proangiogenic growth factors (VEGF, bFGF, NGF) are elevated (Siedlak et al., 1991; Kalaria et al., 1998; Tarkowski et al., 2002; Peng et al., 2004; Mashayekhi and Salehin, 2006) suggesting that angiogenesis may be stimulated. Angiogenesis is tightly regulated by the balance between 
proangiogenic and antiangiogenic factors and it remains unclear whether angiogenesis is actually stimulated or inhibited in AD brains. Since the growth of solid tumors, especially gliomas, which are highly vascularized, is dependent on angiogenesis we evaluated the growth and vascularization of orthotopically implanted gliomas in transgenic mouse models of AD (Tg APPsw and Tg PS1/APPsw) to determine whether tumorally induced angiogenic processes may be altered in the brains of these animals.

\section{Materials and Methods}

Transgenic mouse models of AD. Tg2576 (Tg APPsw) (Hsiao et al., 1996), Tg PS1/APPsw (Holcomb et al., 1998) AD transgenic mice and wild-type littermates (used as control of Tg APPsw and Tg PS1/APPsw) were obtained by crossing heterozygous male Tg PS1/APPsw with wild-type female F1 B6/SJL purchased from The Jackson Laboratory. Animals have been routinely crossed as indicated for many generations and maintained under specific pathogen free condition in ventilated racks with sterile bedding, water and irradiated food. All animal studies involving mice were approved by the Institutional Animal Care and Use Committee of the Roskamp Institute. Tg APPsw mice overproduce the human amyloid precursor protein $(\beta \mathrm{APP})$ containing the Swedish mutation $(\mathrm{K} 670 \mathrm{~N} /$ $\mathrm{M} 671 \mathrm{~L}$ ) under the control of a hamster prion promoter. Tg PS1/APPsw were originally obtained from a cross between Tg APPsw and Tg PS1 (mutant M146L) and display elevated levels of $\mathrm{A} \beta$ compared with $\mathrm{Tg}$ APPsw mice, resulting in an accelerated AD phenotype. Tg APPsw, Tg PS1/APPsw and wild-type littermates used in this study were 32 weeks old. At that age, Tg APPsw have elevated brain levels of $A \beta$ but do not have yet $A \beta$ deposits (Hsiao et al., 1996) whereas Tg PS1/APPsw have substantially higher levels of $A \beta$ compared with Tg APPsw and start to develop few parenchymal $A \beta$ deposits forming senile plaque like structures (Holcomb et al., 1998).

Animal experimental procedures. An orthotopically implanted GL261 murine glioma model was chosen for its known invasive properties and its well documented induction of neoangiogenesis (Zagzag et al., 2000). GL261 were grown in DMEM containing 10\% serum and 1\% penicillin/ streptomycin/fungizone mixture. GL261 cells $\left(10^{5}\right.$ cells in $\left.2 \mu \mathrm{l}\right)$ were intracranially injected in Tg APPsw $(n=12), \operatorname{Tg} \operatorname{PS} 1 / \mathrm{APPsw}(n=8)$ and wild-type littermates $(n=7)$ that were anesthetized with a mixture of ketamine $(80 \mathrm{mg} / \mathrm{kg})$ and xylazine $(10 \mathrm{mg} / \mathrm{kg})$. Tumor cells were implanted in the right frontal lobe with a 25 gauge needle at a depth of 3 $\mathrm{mm}, 1 \mathrm{~mm}$ lateral to midline and $1 \mathrm{~mm}$ anterior to bregma. Animals were monitored daily for any neurological change, weight loss and for their ability to freely access food and water. Mice were humanely euthanatized $21 \mathrm{~d}$ following the implantation of tumor cells and their brains fixed in $4 \%$ paraformaldehyde for pathological evaluations.

Tumor volume measurements. Following $24 \mathrm{~h}$ of fixation in $4 \%$ paraformaldehyde at $4^{\circ} \mathrm{C}$, mouse brains were embedded in paraffin and sectioned in $5 \mu \mathrm{m}$ sections with a microtome. Tumor volumes were calculated from surface area measurements of every $10^{\text {th }}$ tissue section of the tumor following hematoxylin/eosin staining using an image analysis software (ImagePro Plus, Media Cybernetics) as previously described (Wagemakers et al., 2009).

von Willebrand factor immunostaining. von Willebrand factor (VWF) immunostaining was performed on deparaffinized sections that were treated with $20 \mu \mathrm{g} / \mathrm{ml}$ proteinase $\mathrm{K}$ for $15 \mathrm{~min}$ at room temperature. Sections were blocked with the Protein Blok solution from Dako and incubated overnight at $4^{\circ} \mathrm{C}$ with a 1:2000 dilution of a rabbit anti-VWF antibody (Abcam) which has been commonly used to assess vascularization in orthotopically implanted gliomas (Lefranc et al., 2004; Mathieu et al., 2008). Revelation was ensured using the Vectastain Elite ABC kit (Vector Laboratories). To quantify the level of angiogenesis, the surface area occupied by blood vessels (immune-positive for VWF) in brain tumor sections was measured by image analysis (ImagePro Plus, Media Cybernetics) in the most densely vascularized area of each tumor as reported previously for orthotopically implanted gliomas (Kunkel et al., 2001). A minimum of three microscopic fields at $400 \times$ magnification were analyzed per histologic slide and three to five slides randomly dis- tributed throughout the tumor mass were analyzed per tumor which represents an adequate number to evaluate tumoral vascularization (Kunkel et al., 2001). An average surface area of blood vessels was calculated for each tumor and expressed as a percentage area of the microscopic fields analyzed.

Preparation of $A \beta$ peptide. Human recombinant $A \beta 1-42$ (purity $>95 \%$ ) was purchased from rPeptide. The lyophilized peptide was dissolved to $1 \mathrm{mg} / \mathrm{ml}$ in 1,1,1,3,3,3-hexafluoro-2-propanol (HFIP) at $4^{\circ} \mathrm{C}$ to minimize the formation of $\beta$-sheet structures and promote $\alpha$-helical secondary structure. The peptide was allowed to air dry in a chemical fume hood for $1 \mathrm{~h}$ at room temperature, followed by further drying in a Speed Vac (Thermo-Savant) for $30 \mathrm{~min}$. The resulting clear film was resuspended in $100 \%$ DMSO to a concentration of $1 \mathrm{~mm}$, followed by aliquoting and storage at $-80^{\circ} \mathrm{C}$. Such preparations of HFIP-treated human recombinant $\mathrm{A} \beta 1-42$ peptide when analyzed by Western blotting appear to form essentially soluble $A \beta$ dimers and few oligomers of higher molecular weight when resuspended at low $\mu \mathrm{M}$ concentrations (1-10 $\mu \mathrm{M}$ equivalent monomeric concentration) in endothelial cell culture medium following a $24 \mathrm{~h}$ incubation at $37^{\circ} \mathrm{C}$ (Paris et al., 2005). Within the manuscript, the concentrations of $A \beta$ reported do not account for the oligomerization of $\mathrm{A} \beta$ and were calculated using the molecular weight of an A $\beta 1-42$ monomer (molecular weight $=4514.1 \mathrm{Da}$ ).

Proliferation and toxicity assays. Gl261 proliferation was evaluated using the Quick cell proliferation assay kit which is based on the cleavage of a water-soluble salt of tetrazolium (WST) into formazan by mitochondrial dehydrogenase (Biovision). Briefly, GL261 at a low cellular density $\left(550\right.$ cells $\left./ \mathrm{mm}^{2}\right)$ in a 96-well plate were treated with a dose range of HFIP-treated human recombinant $\mathrm{A} \beta 1-42$ dissolved in DMEM medium containing $10 \%$ fetal calf serum and $1 \%$ penicillin/streptomycin/fungizone. After $24 \mathrm{~h}$ at $37^{\circ} \mathrm{C}, 5 \% \mathrm{CO}_{2}$, a $50 \mu \mathrm{l}$ aliquot of culture medium was collected to evaluate the potential toxicity of $\mathrm{A} \beta 1-42$ using a LDH (lactate dehydrogenase) cytotoxicity detection kit (Roche) and $10 \mu \mathrm{l}$ of WST reagent was added to each cell culture well. The cell culture plate was incubated at $37^{\circ} \mathrm{C}, 5 \% \mathrm{CO}_{2}$ for $1 \mathrm{~h}$ and the conversion of WST to formazan quantified at $430 \mathrm{~nm}$ whereas LDH released was monitored at $490 \mathrm{~nm}$ using a microplate reader (BioTek Synergy HT). The experiment was identically repeated, except that the GL261 culture medium was supplemented with $100 \mathrm{ng} / \mathrm{ml}$ EGF (Cytoskeleton Inc). The effect of freshly solubilized HFIP-treated human recombinant $\mathrm{A} \beta 1-42$ was also evaluated on the survival of confluent GL261 cells plated in a 96-well cell culture plate following $24 \mathrm{~h}$ incubation using the LDH cytotoxicity detection kit.

In vitro angiogenesis assay using cocultures of GL261 and human brain microvascular endothelial cells. Capillary network assays were performed as we previously published (Paris et al., 2004a,b, 2005; Patel et al., 2008). Brain Microvascular Endothelial Cells (HBMEC) were obtained from Sciencell and grown in EC medium supplemented with 5\% serum, 1\% penicillin/streptomycin and 1\% Endothelial Cell Growth Supplement (Sciencell). Briefly, GL261 cells were plated onto 24-well plates and grown in DMEM containing $10 \%$ serum and $1 \times$ penicillin/streptomycin/fungizone mixture. Twenty-four hours after plating, confluent GL261 cells were covered with $400 \mu \mathrm{l}$ of Matrigel (BD Bioscience). After Matrigel polymerization at $37^{\circ} \mathrm{C}, 1 \mathrm{ml}$ of DMEM medium containing $10 \%$ serum and $1 \times$ penicillin/streptomycin was added to each well. Similarly, a 24-well plate was coated with $400 \mu \mathrm{l}$ of Matrigel (in the absence of GL261 cells) and incubated with $1 \mathrm{ml}$ of DMEM medium per well for $24 \mathrm{~h}$ at $37^{\circ} \mathrm{C}$ and $5 \% \mathrm{CO}_{2}$. After this incubation period, the medium on the top of the Matrigel layer was replaced with $500 \mu \mathrm{l}$ of EC medium containing $\operatorname{HBMEC}\left(7.5 \times 10^{4}\right.$ cells $\left./ \mathrm{ml}\right)$ and treated with a dose range of HFIPtreated (cf. above) human recombinant A $\beta 1-42(2.5-10 \mu \mathrm{M})$. Control wells received the same volume of vehicle (DMSO) used to dilute the $\mathrm{A} \beta$ peptide. Following $24 \mathrm{~h}$ of incubation at $37^{\circ} \mathrm{C}$ and $5 \% \mathrm{CO}_{2}$, capillary network lengths were quantified by image analysis using the Image Pro Plus software (Media Cybernetics). Capillary network formation experiments were performed in triplicate and four random microscopic fields (10X objective) per well were used to quantify the length of tube like structures. Therefore, 12 microscopic fields were used for each culture condition and results were expressed as an average capillary length observed per $10 \times$ microscopic field in $\mu \mathrm{m}$. 
A

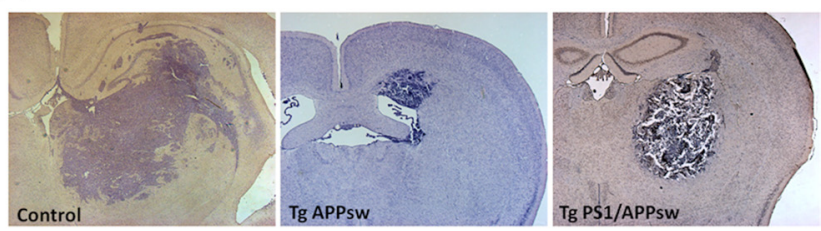

B

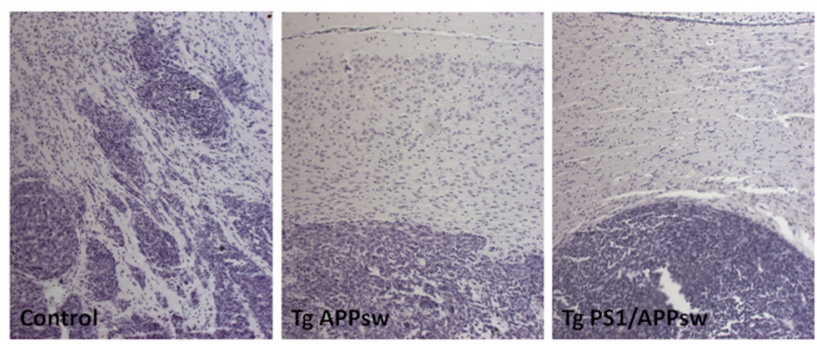

C ${ }_{10}$

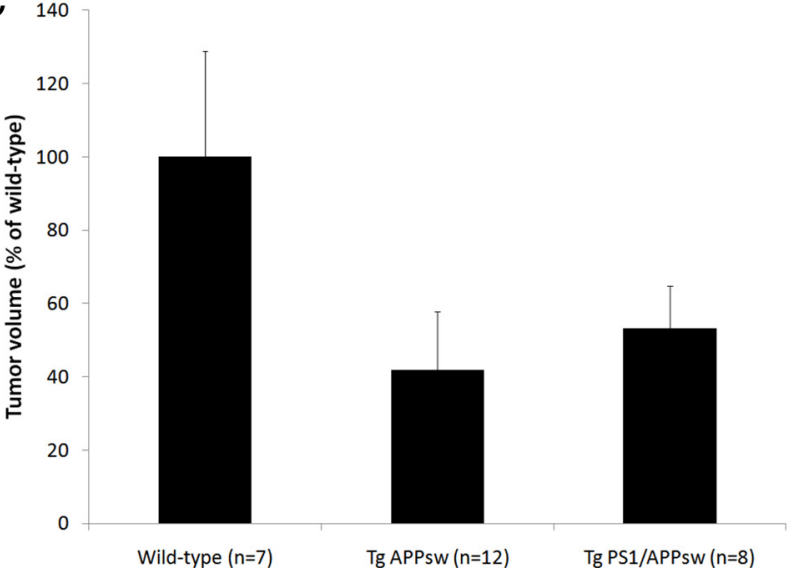

Figure 1. Histologic appearance of GL261 glioma tumors in Tg APPsw, Tg PS1/APPsw and wild-type littermates ( $4 \times$ objective). $\boldsymbol{A}$, Representative examples of tumor surfaces and adjacent parenchyma representing the maximum cross-sectional area of the intracranial glioma following hematoxylin and eosin staining in the different genotypes. Tumors in wild-type mice are surrounded by numerous smaller satellite tumors in contrast with tumors from Tg APPsw and Tg PS1/APPsw mice. B, Examples of tumor surfaces at higher magnification $(20 \times$ objective) depicting the presence of peritumoral satellites in wild-type mice suggestive of a more invasive growth pattern than in $\mathrm{Tg}$ APPsw and Tg PS1/APPsw mice. C, Histogram representing the average tumor volume estimated in $\mathrm{Tg}$ APPsw, $\mathrm{Tg}$ PS1/APPsw and wild-type littermates. ANOVA revealed a significant main effect of the genotypes on tumor growth $(p<0.005)$. Post hoc comparisons show a significant difference in tumor volume between wild-type littermates, $\operatorname{Tg}$ APPsw $(p<0.005), \operatorname{Tg}$ PS1/APPsw $(p<0.03)$ but no significant difference between the tumor volume of $\mathrm{Tg}$ APPsw and $\mathrm{Tg}$ PS1/APPsw mice $(p=0.486)$.

Effect of brain homogenates on capillary morphogenesis. Brains (without the cerebellum) from a 73-week-old Tg PS1/APPsw and wild-type littermate were weighted and homogenized by sonication in ice-cold PBS containing a $1 \times$ mixture of protease inhibitor (Pierce) to a concentration of $188.5 \mathrm{mg} / \mathrm{ml}$ extract. A $1 \%$ volume to volume brain extract was diluted in the HBMEC culture medium (i.e., $1885 \mu \mathrm{g}$ of brain extract per milliliter of culture medium) surrounding HBMEC at the time of plating on Matrigel. HBMEC were incubated for $24 \mathrm{~h}$ before evaluating capillary morphogenesis by image analysis as indicated above.

\section{Results}

Growth of orthotopically implanted glioma tumors in transgenic mouse models of $\mathrm{AD}$

A significant inhibition of tumor growth was observed in $\mathrm{Tg}$ APPsw and Tg PS1/APPsw compared with their nontransgenic littermates. Tumor volumes were reduced on average by $\sim 60 \%$

\section{A}
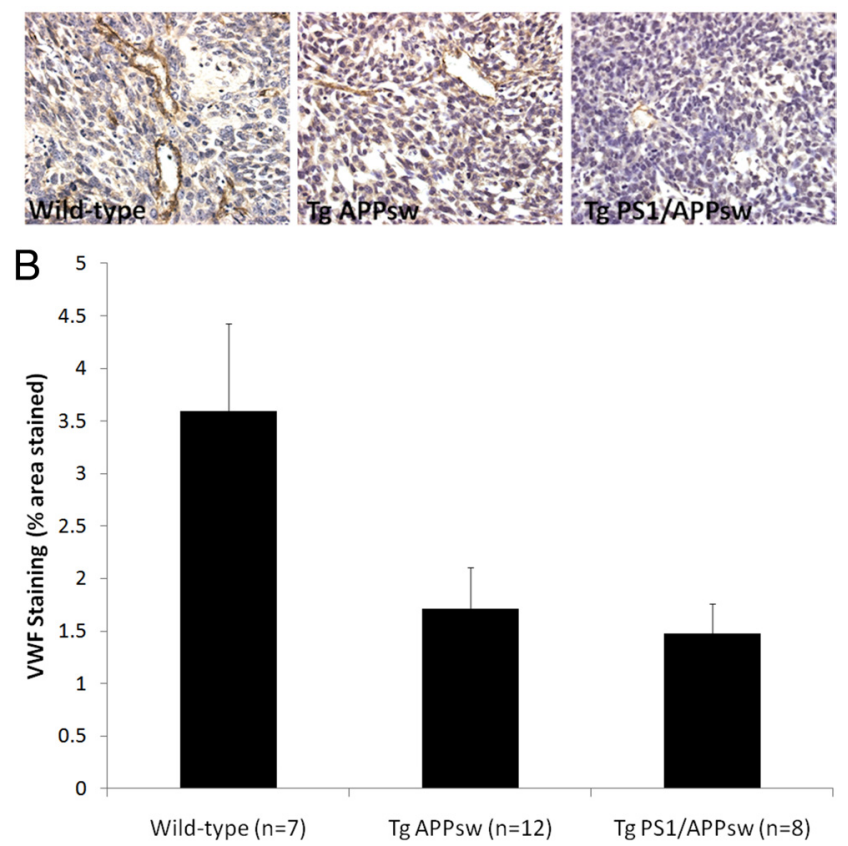

Figure 2. A, Representative pictures ( $60 \times$ objective) showing VWF immunostaining depicting newly formed blood vessels in tumoral sections of Tg APPsw, Tg PS1/APPsw and wild-type littermates. VWF staining reveals higher blood vessel density in glioma tumors from wild-type mice compared with glioma tumors implanted in $\mathrm{Tg}$ APPsw and $\mathrm{Tg}$ PS1/APPsw mice. $\boldsymbol{B}$, The histogram represents the percentage area of microscopic fields covered by VWFimmunopositive blood vessels quantified by image analysis. ANOVA revealed a significant main effect of the genotypes on the amount of VWF staining per microscopic area analyzed ( $p<$ 0.04). Post hoc analyses show that vascularization is significantly reduced in tumor sections from Tg APPsw $(p<0.03)$ and Tg PS1/APPsw $(p<0.02)$ compared with wild-type littermates but no significant difference was observed between $\mathrm{Tg}$ PS1/APPsw and $\mathrm{Tg}$ APPsw mice $(p=0.759)$.

in Tg APPsw and by 50\% in Tg PS1/APPsw compared with their wild-type littermates (Fig. 1). Tumors in wild-type animals were surrounded by numerous small satellite tumors compared with glioma tumors in the brain of Tg APPsw and Tg PS1/APPsw mice suggesting a more invasive growth pattern of glioma tumors in wild-type mice (Fig. 1). We next assessed glioma tumor vascularization by immunostaining for VWF as angiogenesis is one of the characteristics of malignant tumors. Intra-tumoral vascular density was significantly reduced by $\sim 60 \%$ in Tg PS1/APPsw and by $\sim 50 \%$ in Tg APPsw compared with their wild-type littermates (Fig. 2) showing that angiogenesis is inhibited in tumors intracranially implanted in transgenic mouse models of AD.

We evaluated the potential impact of freshly solubilized $A \beta$ on GL261 proliferation and survival using GL261 cells plated at a low density and observed that A $\beta$ did not affect GL261 proliferation and was not toxic even at a high concentration $(10 \mu \mathrm{M})$, following a $24 \mathrm{~h}$ incubation period, under regular culture conditions (Fig. 3 ). We also repeated the experiments using confluent GL261 cells and observed that $\mathrm{A} \beta$ did not induce cellular toxicity in GL261 cells (data not shown) showing that the inhibition of GL261 tumor growth observed in transgenic mice overexpressing $\mathrm{A} \beta$ is not related to a direct cytotoxic effect of $\mathrm{A} \beta$ in tumor cells.

\section{Effect of brain homogenates from Tg PS1/APPsw and} wild-type mice on in vitro angiogenesis

Brain homogenates from 73-week-old Tg PS1/APPsw and wildtype littermate were diluted to $1 \%$ (volume to volume) in the 

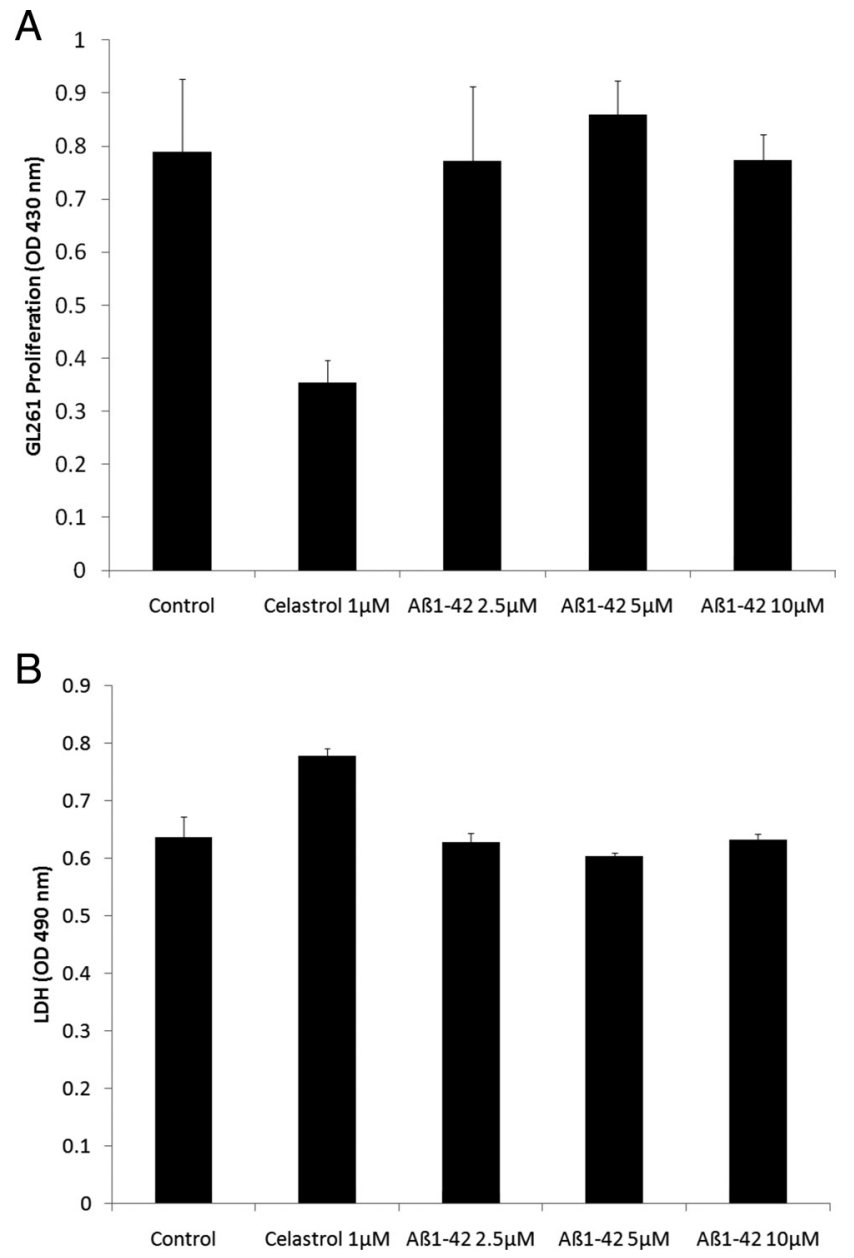

Figure 3. Effect of human recombinant $A \beta 1-42$ on the proliferation and survival of GL261 tumor cells. $A$, The histogram depicts the effect of A $\beta 1-42$ on GL261 proliferation. The NF $\kappa B$ inhibitor celastrol was used as a positive control and significantly inhibited the proliferation of GL261 cells $(p<0.001)$. ANOVA reveals no statistically significant main effect of $A \beta$ dose ( $p=0.788$ ) showing that $A \beta 1-42$ does not affect the proliferation of GL261 cells. $B$, The histogram depicts the effect of $A \beta 1-42$ on GL261 survival estimated by the release of $L D H$ in the culture medium. Slight toxicity of the positive control (celastrol) was observed $(p<0.01)$. ANOVA shows no statistically significant main effect of $A \beta$ dose $(p=0.305)$ demonstrating that at the doses used, $A \beta 1-42$ is not cytotoxic to GL261 cells.

culture media surrounding HBMEC at the time of plating on Matrigel. Following $24 \mathrm{~h}$ of culture, the formation of capillary networks was analyzed by image analysis. A 55\% reduction in capillary network length was observed when Tg PS1/APPsw brain homogenate was added to the culture medium of HBMEC compared with wild-type brain homogenate showing that brain extracts from Tg PS1/APPsw can impair the formation of capillary-like networks in vitro (Fig. 4). No difference in LDH released in the culture media surrounding HBMEC was observed between $\mathrm{Tg}$ PS1/APPsw and wild-type brain homogenates treatments (data not shown) suggesting that the Tg PS1/APPsw brain homogenate is not directly cytotoxic to HBMEC.

Effect of $A \boldsymbol{\beta}$ on angiogenesis stimulated by glioma tumor cells We studied the effect of GL261 tumor cells on capillary formation by coculturing human brain microvascular cells (HBMEC) with GL261 since angiogenesis is triggered by tumor expression of various proangiogenic factors in gliomas (Kaur et al., 2004). We observed that glioma GL261 cells stimulate the formation of capillary-like networks by HBMEC (Fig. 5) and that freshly sol-
A

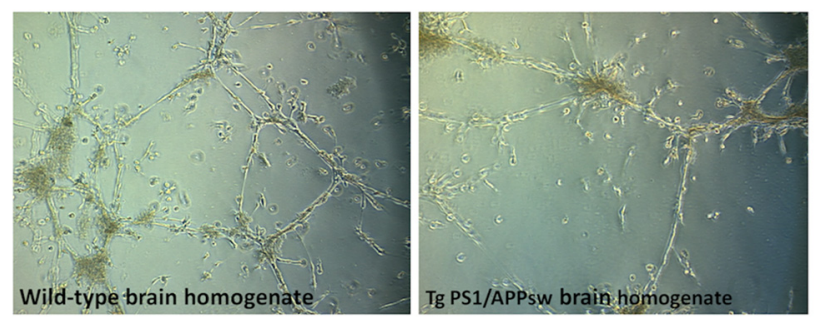

B

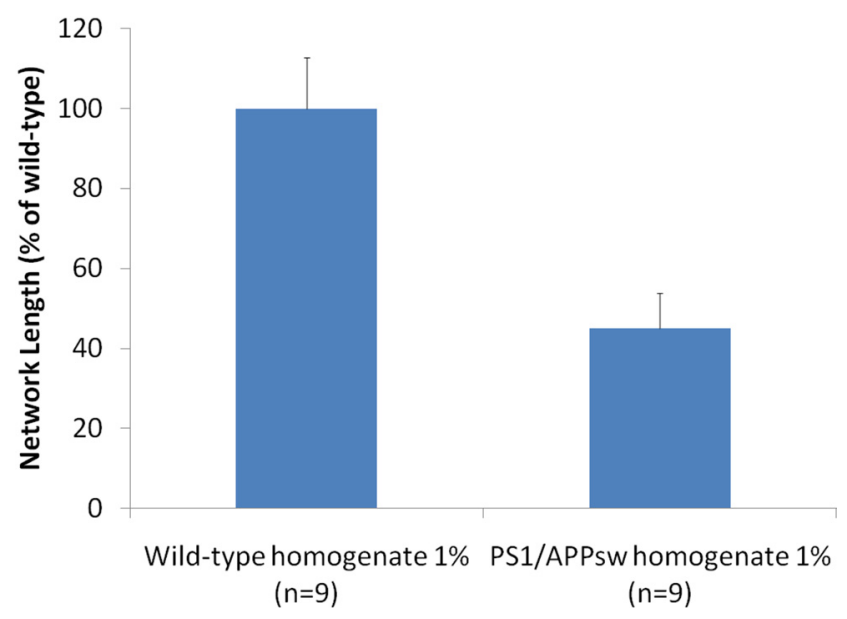

Figure 4. Effect of brain homogenates from $\mathrm{Tg}$ PS1/APPsw and wild-type mice on capillary morphogenesis. $A$, Representative photomicrographs ( $10 \times$ objective) showing the formation of tube-like structures by HBMEC when plated on a layer of Matrigel in the presence of $1 \%$ of brain homogenate from wild-type and Tg PS1/APPsw mice. $\boldsymbol{B}$, Histogram representing the quantification of capillary network length formed by HBMEC in the presence of wild-type and Tg PS1/APPsw brain homogenates. A statistically significant inhibition of capillary formation was observed $(p<0.01)$ when HBMEC were cultured in the presence of Tg PS1/APPsw brain homogenate compared with wild-type brain homogenate.

ubilized human recombinant $\mathrm{A} \beta 1-42$ dose-dependently inhibits the formation of capillary-like structures stimulated by GL261 cells. In these cocultures, cellular contact between HBMEC and GL261 cells was precluded by a layer of Matrigel suggesting that diffusible factors produced by GL261 were acting on HBMEC to stimulate the formation of capillary-like network and that $\mathrm{A} \beta$ is able to inhibit the activity of these diffusible factors. $\mathrm{LDH}$ release was assessed in the culture medium surrounding the capillary networks and no increased $\mathrm{LDH}$ was observed following $\mathrm{A} \beta$ treatment (Fig. 5) showing that the inhibition of angiogenesis induced by $\mathrm{A} \beta$ was achieved without inducing direct cellular toxicity to either GL261 cells or HBMEC.

\section{Discussion}

Various proangiogenic growth factors and proinflammatory mediators with known angiogenic stimulatory activity are upregulated in AD brains (Siedlak et al., 1991; Kalaria et al., 1998; Tarkowski et al., 2002; Peng et al., 2004; Mashayekhi and Salehin, 2006), which could suggest that excessive or aberrant angiogenic processes may contribute to the pathology of AD. The presence of angiogenic proteins such as VEGF and TIMP-1 in isolated AD microvessels has led to the supposition that the cerebral microvasculature is in a "proangiogenic state" in $\mathrm{AD}$ (Thirumangalakudi et al., 2006). Others have suggested that anti-angiogenic therapies could be beneficial since nonsteroidal anti-inflammatory drugs (NSAIDs) and statins, which can inhibit angiogenesis, have been 


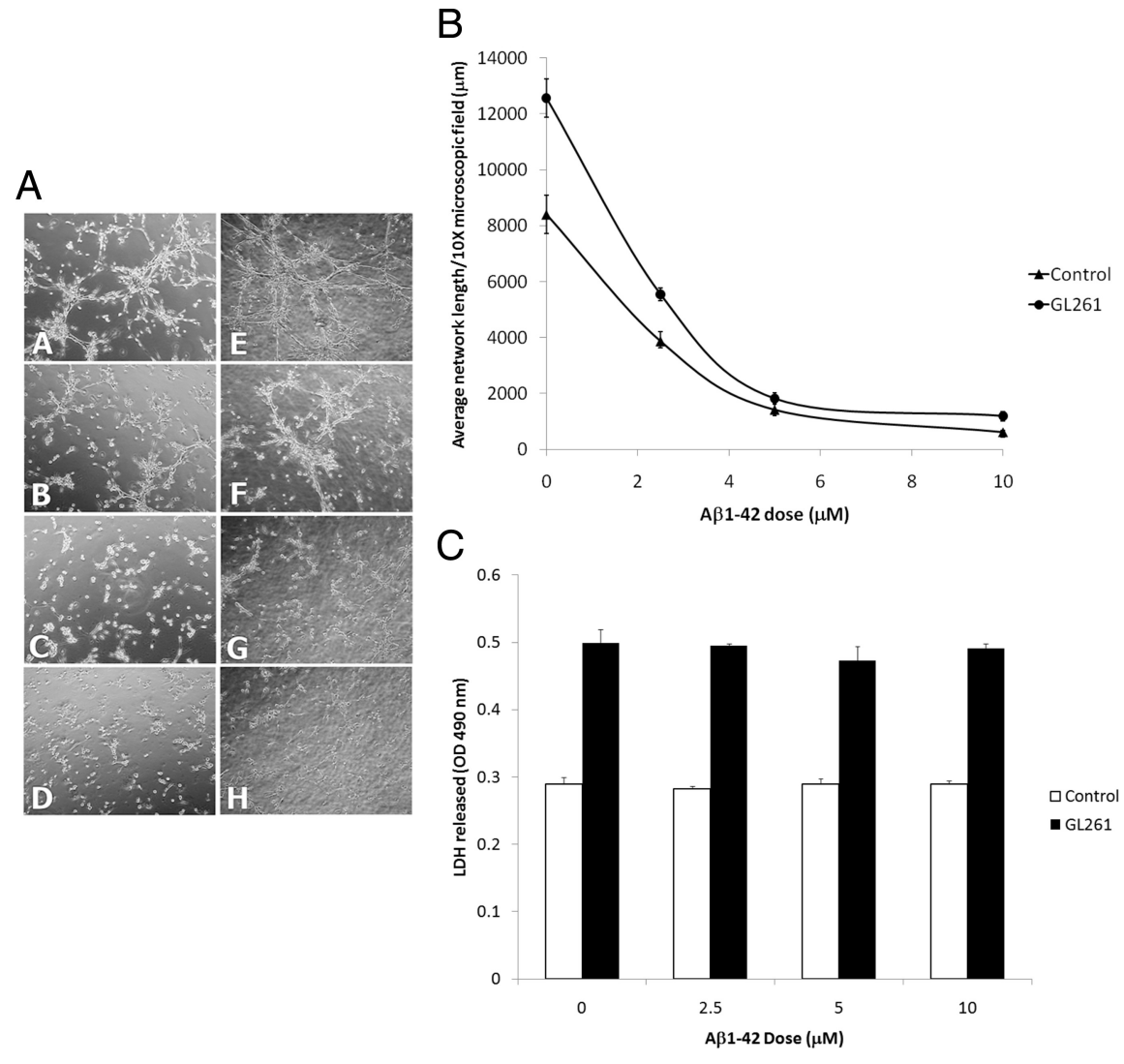

Figure 5. Effect of human recombinant A $\beta 1-42$ on the angiogenesis stimulated by GL261 glioma cells. $A$, Representative photomicrographs ( $10 \times$ objective) showing the formation of tube-like structures by $\mathrm{HBMEC}$ when plated on a layer of Matrigel in regular culture conditions $(\boldsymbol{A A})$ and in coculture with GL261 cells ( $\boldsymbol{A E}$ ). Disruption of capillary network formation was observed with ranging concentrations of $A \beta 1-42$ in regular culture conditions ( $A B 2.5 \mu \mathrm{m}, A C 5 \mu \mathrm{M}, A D 10 \mu \mathrm{M} A \beta 1-42)$ and in coculture with GL261 cells ( $\boldsymbol{A F} 2.5 \mu \mathrm{M}, \mathrm{G} 5 \mu \mathrm{M}, \mathrm{H} 10 \mu \mathrm{M} A \beta 1-42$ ). $\boldsymbol{B}$, Histogram representing the average length of capillary like structures formed by HBMEC in response to a dose range of $A \beta 1-42$ in regular culture conditions (control) and in coculture with GL261 glioma cells (GL261). ANOVA revealed a significant main effect of GL261 cells $(p<0.001)$ and of A $\beta$ doses $(p<0.001)$ on capillary network formation. Post hoc comparisons show statistically significant differences between the control culture conditions and the GL261 cocultures $(p<0.001$ ) showing that GL261 glioma cells stimulate capillary like network formations by HBMEC. In addition, significant inhibition of capillary like formation was observed for all the doses of $A \beta$ tested in regular and coculture conditions $(p<0.01)$. C, The histogram depicts the impact of human recombinant A $\beta 1-42$ on $\mathrm{LDH}$ released in regular culture conditions (control) and in coculture with GL261 glioma cells (GL261). ANOVA revealed no significant main effect of A $\beta$ doses ( $p=0.306$ ) showing that at the doses used, A $\beta 1-42$ did not induce cytotoxicity to HBMEC or GL261 cells and HBMEC when cocultured.

associated with beneficial outcomes in $\mathrm{AD}$ patients (Vagnucci and $\mathrm{Li}, 2003$ ). However, recent clinical trials with statins or NSAIDs have failed to provide evidence of protection in AD patients (Breitner et al., 2009; McGuinness et al., 2009). In AD brains, capillary density is low within amyloid plaques but high in regions that immediately surround them, suggesting that amyloid plaques exclude capillaries or lead to their degeneration (Kawai et al., 1990). Endothelial cell activation has been documented in an AD mouse model (APP23) as evidenced by increased $\beta 3$-integrin expression restricted to $\beta$-amyloid-positive vessels (Schultheiss et al., 2006) suggesting that angiogenesis may occur in this transgenic mouse model of AD.

Angiogenesis is a tightly regulated process in which the outcome critically depends upon the balance between proangiogenic and anti-angiogenic factors. Endostatin, a fragment of collagen XVIII with potent antiangiogenic properties, has been shown to accumulate in perivascular and cortical plaques of $\mathrm{AD}$ patients (Deininger et al., 2002). Moreover, we have shown that pathological levels of soluble forms of $A \beta$ peptides are anti-angiogenic in a multitude of in vitro and in vivo experimental models and antag- onize both VEGF- and bFGF-induced angiogenesis (Paris et al., 2004a,b, 2005; Patel et al., 2008). Since VEGF and bFGF are critical not only to initiate angiogenesis but also to maintain the integrity of the cerebrovasculature, our data suggest that by antagonizing angiogenic growth factors, pathological levels of $A \beta$ may induce cerebrovascular damage possibly leading to capillary rarefaction. Others have replicated such findings (Cantara et al., 2004; Donnini et al., 2006, 2010; Boscolo et al., 2007; Drago et al., 2007; Hayashi et al., 2009; Solito et al., 2009) and the hypothesis that an aberrant angiogenic process may contribute to $\mathrm{AD}$ dementia is now emerging (Watson et al., 2005; Wu et al., 2005; Zlokovic, 2005; Deane and Zlokovic, 2007).

To determine whether the overall environment is pro- or anti-angiogenic in models of the $\mathrm{AD}$ brain, we examined the growth of a tumor type that is critically dependent upon angiogenesis. Specifically, we assessed the growth and vascularization of an orthotopically implanted glioma model in Tg APPsw and Tg PS1/ APPsw mice, two transgenic mouse models of AD. Gliomas are the most aggressive type of primary brain tumor and are associated with a high degree of angiogenesis (Plate and Risau, 1995). During tumorigenesis, angiogenesis is triggered by tumor expression of various proangiogenic factors (Hanahan and Folkman, 1996) which are induced by physiological stimuli such as hypoxia (Kaur et al., 2004).

Pathological evaluation of the tumor samples shows that glioma growth is inhibited in the brains of Tg APPsw and Tg PS1/APPsw compared with their wildtype littermates. In addition, a decreased VWF immunostaining in glioma tumors from transgenic mouse models of $\mathrm{AD}$ was observed indicating a decreased angiogenesis in glioma tumors. Although tumoral angiogenesis is associated with rapid endothelial cell turnover compared with healthy brain tissue, our data suggest that angiogenesis may be aborted in transgenic mouse models of AD under pathological conditions. Interestingly, addition of Tg PS1/APPsw brain homogenate to HBMEC cultures on a Matrigel layer impairs their differentiation into capillary networks further suggesting that the brain environment of Tg PS1/APPsw mice does not support angiogenesis.

Pathological levels of $\mathrm{A} \beta$ are clearly antiangiogenic both in vitro and in vivo (Paris et al., 2004a,b; Donnini et al., 2010) and appear to antagonize VEGF-R2 (the main receptor involved in angiogenesis) in human brain microvascular endothelial cells (Patel et al., 2010). Interestingly, $A \beta$ immunotherapy leading to a reduction of both soluble and insoluble $A \beta$ is associated with increased angiogenesis in Tg PS1/APP mice (Biscaro et al., 2009) which supports the suggestion that $\mathrm{A} \beta$ is an angiogenic suppressor in the brain. We therefore investigated the impact of $A \beta$ on glioma-induced angiogenesis using a coculture model using 
GL261 cells and HBMEC. We found that GL261 glioma cells stimulate capillary like network formation by HBMEC whereas $\mathrm{A} \beta$ dose-dependently inhibits this effect. We did not observe any gross effect of A $\beta$ even at high doses on GL261 glioma cell proliferation and survival in vitro suggesting that the reduction of tumor growth observed in transgenic mice overexpressing $A \beta$ is not related to a direct effect of $\mathrm{A} \beta$ on tumoral cell viability or proliferation. In old Tg APPsw brains (21-23 months), the total amount of $A \beta 40$ and $A \beta 42$ most closely resemble $A \beta$ levels in the $\mathrm{AD}$ brain and is $\sim 26,000 \mathrm{pmol} / \mathrm{g}$ (Kawarabayashi et al., 2001). On average, the weight of an adult mouse brain is $\sim 0.451 \mathrm{~g}$ for a volume of $\sim 0.5 \mathrm{ml}$ (Jones et al., 2009). If we approximate that $\mathrm{A} \beta$ is uniformly distributed in the tissue, we can estimate the total brain $\mathrm{A} \beta$ concentration to be $\sim 106 \mu \mathrm{g} / \mathrm{ml}$ in Tg APPsw mice which is well within the range of the $\mathrm{A} \beta$ concentrations used in our in vitro experiments showing that $\mathrm{A} \beta$ impairs the angiogenesis stimulated by GL261 glioma cells. The exact nature of the A $\beta$ species responsible for the antiangiogenic activity of $A \beta$ remains unclear. We have determined previously that preparation of $A \beta$ peptides containing soluble $\mathrm{A} \beta$ oligomers are more potently antiangiogenic than preparations that do not contain soluble $\mathrm{A} \beta$ oligomers. In particular, we have shown that the mutant Dutch $\mathrm{A} \beta$ is more potently antiangiogenic than wild-type $\mathrm{A} \beta$ because of its ability to form soluble $\mathrm{A} \beta$ oligomers more rapidly than wildtype $\mathrm{A} \beta$ at low concentration (Paris et al., 2005).

Decreased capillary density has been documented in $\mathrm{AD}$ brains (Hashimura et al., 1991; Kimura et al., 1991; Buée et al., 1997; Fischer et al., 1997; Bouras et al., 2006; Kitaguchi et al., 2007) and in the brains of different AD mouse models (Paris et al., 2004b; Lee et al., 2005; Kouznetsova et al., 2006; Meyer et al., 2008; Takeuchi et al., 2008; Hayashi et al., 2009) despite increased levels of angiogenic growth factors (Kalaria et al., 1998; Tarkowski et al., 2002; Lopez-Lopez et al., 2007; Bürger et al., 2009 ) suggesting that the angiogenic process may be aborted in $\mathrm{AD}$ brains. We propose that $\mathrm{A} \beta$ may be one of the key factors responsible for an opposition of angiogenic growth factor signaling in $\mathrm{AD}$ and therefore may directly contribute to cerebrovascular pathologies in $\mathrm{AD}$ by impairing vascular maintenance and preventing the regeneration of the endothelium in response to vascular injuries. The antiangiogenic activity of $\mathrm{A} \beta$ may explain why $\mathrm{AD}$ patients appear particularly vulnerable to cerebrovascular infarcts (Snowdon et al., 1997). Capillary rarefaction appears to contribute to the pathological and clinical presentation of $\mathrm{AD}$ since reduction in capillary number appears to correlate with the severity of dementia in AD (using the Clinical Dementia Rating Scale) and with a higher burden of $\mathrm{A} \beta$ deposits and neurofibrillary tangles (Bouras et al., 2006).

Interestingly, donepezil, an acetylcholinesterase inhibitor frequently prescribed to $\mathrm{AD}$ patients, has been shown to stimulate brain angiogenesis in mice (Narimatsu et al., 2009). Overexpression of the proangiogenic human hepatocyte growth factor in the brain of a mouse model of $\mathrm{AD}$ has been shown to promote a significant recovery of vessel density in the hippocampus and to reverse cognitive deficits induced by $\mathrm{A} \beta$ (Takeuchi et al., 2008). In addition, administration of the angiogenic insulin-like growth factor I (Carro and Torres-Aleman, 2006; Lopez-Lopez et al., 2007) or VEGF (Spuch et al., 2010) increase brain vascular density and improve cognition in transgenic mouse models of $\mathrm{AD}$ suggesting that proangiogenic therapies may be beneficial in $\mathrm{AD}$.

Altogether our data show that the brains of transgenic mouse models of $\mathrm{AD}$ overexpressing $\mathrm{A} \beta$ do not constitute an adequate environment to sustain angiogenesis despite increased intracerebral levels of angiogenic growth factors (Lopez-Lopez et al., 2007;
Bürger et al., 2009). For this study, 32-week-old animals were used. At that age, Tg APPsw mice do not present $\beta$-amyloid deposits whereas Tg PS1/APPsw mice have only a few A $\beta$ deposits. The fact that glioma growth and vascularization was inhibited in the absence of significant $\mathrm{A} \beta$ deposition is in agreement with our previous observations showing that soluble forms of $A \beta$ are antiangiogenic whereas fibrillar/aggregated forms of $\mathrm{A} \beta$ are not (Paris et al., 2005) and further suggest that angiogenesis inhibition may be an early event contributing to cerebrovascular dysfunctions in $\mathrm{AD}$. Interestingly, there are reports of reduced incidence of cancer in AD patients (Tirumalasetti et al., 1991; DeSouky, 1992; Yamada et al., 1999; Yashin et al., 2009; Roe et al., 2010) which may be the result of defective angiogenic functions in these patients suggesting a clinical or potentially therapeutic aspect to this effect.

\section{References}

Bell RD, Zlokovic BV (2009) Neurovascular mechanisms and blood-brain barrier disorder in Alzheimer's disease. Acta Neuropathol 118:103-113.

Bell RD, Deane R, Chow N, Long X, Sagare A, Singh I, Streb JW, Guo H, Rubio A, Van Nostrand W, Miano JM, Zlokovic BV (2009) SRF and myocardin regulate LRP-mediated amyloid-beta clearance in brain vascular cells. Nat Cell Biol 11:143-153.

Biscaro B, Lindvall O, Hock C, Ekdahl CT, Nitsch RM (2009) Abeta immunotherapy protects morphology and survival of adult-born neurons in doubly transgenic APP/PS1 mice. J Neurosci 29:14108-14119.

Boscolo E, Folin M, Nico B, Grandi C, Mangieri D, Longo V, Scienza R, Zampieri P, Conconi MT, Parnigotto PP, Ribatti D (2007) Beta amyloid angiogenic activity in vitro and in vivo. Int J Mol Med 19:581-587.

Bouras C, Kövari E, Herrmann FR, Rivara CB, Bailey TL, von Gunten A, Hof PR, Giannakopoulos P (2006) Stereologic analysis of microvascular morphology in the elderly: Alzheimer disease pathology and cognitive status. J Neuropathol Exp Neurol 65:235-244.

Breitner JC, Haneuse SJ, Walker R, Dublin S, Crane PK, Gray SL, Larson EB (2009) Risk of dementia and AD with prior exposure to NSAIDs in an elderly community-based cohort. Neurology 72:1899-1905.

Buée L, Hof PR, Delacourte A (1997) Brain microvascular changes in Alzheimer's disease and other dementias. Ann NY Acad Sci 826:7-24.

Bürger S, Noack M, Kirazov EP, Naydenov CL, Kouznetsova E, Yafai Y, Schliebs R (2009) Vascular endothelial growth factor (VEGF) affects processing of amyloid precursor protein and beta-amyloidogenesis in brain slice cultures derived from transgenic Tg2576 mouse brain. Int J Dev Neurosci 27:517-523.

Cantara S, Donnini S, Morbidelli L, Giachetti A, Schulz R, Memo M, Ziche M (2004) Physiological levels of amyloid peptides stimulate the angiogenic response through FGF-2. FASEB J 18:1943-1945.

Carro E, Torres-Aleman I (2006) Serum insulin-like growth factor I in brain function. Keio J Med 55:59-63.

Chow N, Bell RD, Deane R, Streb JW, Chen J, Brooks A, Van Nostrand W, Miano JM, Zlokovic BV (2007) Serum response factor and myocardin mediate arterial hypercontractibility and cerebral blood flow dysregulation in Alzheimer's phenotype. Proc Natl Acad Sci U S A 104:823-828.

Deane R, Zlokovic BV (2007) Role of the blood-brain barrier in the pathogenesis of Alzheimer's disease. Curr Alzheimer Res 4:191-197.

Deininger MH, Fimmen BA, Thal DR, Schluesener HJ, Meyermann R (2002) Aberrant neuronal and paracellular deposition of endostatin in brains of patients with Alzheimer's Disease. J Neurosci 22:10621-10626.

DeSouky AL (1992) The relationship between cancer and Alzheimer's disease. J Am Geriatr Soc 40:1075.

Donnini S, Cantara S, Morbidelli L, Giachetti A, Ziche M (2006) FGF-2 overexpression opposes the beta amyloid toxic injuries to the vascular endothelium. Cell Death Differ 13:1088-1096.

Donnini S, Solito R, Cetti E, Corti F, Giachetti A, Carra S, Beltrame M, Cotelli F, Ziche M (2010) Abeta peptides accelerate the senescence of endothelial cells in vitro and in vivo, impairing angiogenesis. FASEB J 24:2385-2395.

Drago D, Folin M, Baiguera S, Tognon G, Ricchelli F, Zatta P (2007) Comparative effects of Abeta(1-42)-Al complex from rat and human amyloid on rat endothelial cultures. J Alzheimers Dis 11:33-44.

Fischer VW, Siddiqi A, Yusufaly Y (1997) Altered angioarchitecture in se- 
lected areas of brains with Alzheimer's disease. Acta Neuropathol (Berl) 79:672-679.

Hanahan D, Folkman J (1996) Patterns and emerging mechanisms of the angiogenic switch during tumorigenesis. Cell 86:353-364.

Hashimura T, Kimura T, Miyakawa T (1991) Morphological changes of blood vessels in the brain with Alzheimer's disease. Jpn J Psychiatry Neurol 45:661-665.

Hayashi S, Sato N, Yamamoto A, Ikegame Y, Nakashima S, Ogihara T, Morishita R (2009) Alzheimer's disease-associated peptide, Amyloid b40, inhibits vascular regeneration with induction of endothelial autophagy. Arterioscler Thromb Vasc Biol 29:1909-1915.

Hoffman LB, Schmeidler J, Lesser GT, Beeri MS, Purohit DP, Grossman HT, Haroutunian V (2009) Less Alzheimer disease neuropathology in medicated hypertensive than nonhypertensive persons. Neurology 72:17201726.

Holcomb L, Gordon MN, McGowan E, Yu X, Benkovic S, Jantzen P, Wright K, Saad I, Mueller R, Morgan D, Sanders S, Zehr C, O'Campo K, Hardy J, Prada CM, Eckman C, Younkin S, Hsiao K, Duff K (1998) Accelerated Alzheimer-type phenotype in transgenic mice carrying both mutant amyloid precursor protein and presenilin 1 transgenes. Nat Med 4:97-100.

Hsiao K, Chapman P, Nilsen S, Eckman C, Harigaya Y, Younkin S, Yang F, Cole G (1996) Correlative memory deficits, Abeta elevation, and amyloid plaques in transgenic mice. Science 274:99-102.

Iadecola C (2004) Neurovascular regulation in the normal brain and in Alzheimer's disease. Nat Rev Neurosci 5:347-360.

Jones AR, Overly CC, Sunkin SM (2009) The Allen Brain Atlas: 5 years and beyond. Nat Rev Neurosci 10:821-828.

Kalaria RN, Cohen DL, Premkumar DR, Nag S, LaManna JC, Lust WD (1998) Vascular endothelial growth factor in Alzheimer's disease and experimental cerebral ischemia. Brain Res Mol Brain Res 62:101-105.

Kaur B, Tan C, Brat DJ, Post DE, Van Meir EG (2004) Genetic and hypoxic regulation of angiogenesis in gliomas. J Neurooncol 70:229-243.

Kawarabayashi T, Younkin LH, Saido TC, Shoji M, Ashe KH, Younkin SG (2001) Age-dependent changes in brain, CSF, and plasma amyloid (beta) protein in the Tg2576 transgenic mouse model of Alzheimer's disease. J Neurosci 21:372-381.

Kawai M, Kalaria RN, Harik SI, Perry G (1990) The relationship of amyloid plaques to cerebral capillaries in Alzheimer's disease. Am J Pathol 137:1435-1446.

Kimura T, Hashimura T, Miyakawa T (1991) Observations of microvessels in the brain with Alzheimer's disease by the scanning electron microscopy. Jpn J Psychiatry Neurol 45:671-676.

Kitaguchi H, Ihara M, Saiki H, Takahashi R, Tomimoto H (2007) Capillary beds are decreased in Alzheimer's disease, but not in Binswanger's disease. Neurosci Lett 417:128-131.

Kouznetsova E, Klingner M, Sorger D, Sabri O, Grossmann U, Steinbach J, Scheunemann M, Schliebs R (2006) Developmental and amyloid plaque-related changes in cerebral cortical capillaries in transgenic Tg2576 Alzheimer mice. Int J Dev Neurosci 24:187-193.

Kunkel P, Ulbricht U, Bohlen P, Brockmann MA, Fillbrandt R, Stavrou D, Westphal M, Lamszus K (2001) Inhibition of glioma angiogenesis and growth in vivo by systemic treatment with a monoclonal antibody against vascular endothelial growth factor receptor-2. Cancer Res 61:6624-6628.

Lee GD, Aruna JH, Barrett PM, Lei DL, Ingram DK, Mouton PR (2005) Stereological analysis of microvascular parameters in a double transgenic model of Alzheimer's disease. Brain Res Bull 65:317-322.

Lefranc F, Mijatovic T, Mathieu V, Rorive S, Decaestecker C, Debeir O, Brotchi J, Van Ham P, Salmon I, Kiss R (2004) Characterization of gastrininduced proangiogenic effects in vivo in orthotopic U373 experimental human glioblastomas and in vitro in human umbilical vein endothelial cells. Clin Cancer Res 10:8250-8265.

Lopez-Lopez C, Dietrich MO, Metzger F, Loetscher H, Torres-Aleman I (2007) Disturbed cross talk between insulin-like growth factor 1 and AMP-activated protein kinase as a possible cause of vascular dysfunction in the amyloid precursor protein/presenilin 2 mouse model of Alzheimer's disease. J Neurosci 27:824-831.

Mashayekhi F, Salehin Z (2006) Cerebrospinal fluid nerve growth factor levels in patients with Alzheimer's disease. Ann Saudi Med 26:278-282.

Mathieu V, De Nève N, Le Mercier M, Dewelle J, Gaussin JF, Dehoux M, Kiss $\mathrm{R}$, Lefranc F (2008) Combining bevacizumab with temozolomide increases the antitumor efficacy of temozolomide in a human glioblastoma orthotopic xenograft model. Neoplasia 10:1383-1392.
McGuinness B, Craig D, Bullock R, Passmore P (2009) Statins for the prevention of dementia. Cochrane Database Syst Rev (2):CD003160.

Meyer EP, Ulmann-Schuler A, Staufenbiel M, Krucker T (2008) Altered morphology and 3D architecture of brain vasculature in a mouse model for Alzheimer's disease. Proc Natl Acad Sci U S A 105:3587-3592.

Narimatsu N, Harada N, Kurihara H, Nakagata N, Sobue K, Okajima K (2009) Donepezil improves cognitive function in mice by increasing the production of insulin-like growth factor-I in the hippocampus. J Pharmacol Exp Ther 330:2-12.

Paris D, Townsend K, Quadros A, Humphrey J, Sun J, Brem S, WotoczekObadia M, DelleDonne A, Patel N, Obregon DF, Crescentini R, Abdullah L, Coppola D, Rojiani AM, Crawford F, Sebti SM, Mullan M (2004a) Inhibition of angiogenesis by Abeta peptides. Angiogenesis 7:75-85.

Paris D, Patel N, DelleDonne A, Quadros A, Smeed R, Mullan M (2004b) Impaired angiogenesis in a transgenic mouse model of cerebral amyloidosis. Neurosci Lett 366:80-85.

Paris D, Ait-Ghezala G, Mathura VS, Patel N, Quadros A, Laporte V, Mullan M (2005) Anti-angiogenic activity of the mutant Dutch A(beta) peptide on human brain microvascular endothelial cells. Brain Res Mol Brain Res 136:212-230.

Patel NS, Quadros A, Brem S, Wotoczek-Obadia M, Mathura VS, Laporte V, Mullan M, Paris D (2008) Potent anti-angiogenic motifs within the Alzheimer beta-amyloid peptide. Amyloid 15:5-19.

Patel NS, Mathura VS, Bachmeier C, Beaulieu-Abdelahad D, Laporte V, Weeks O, Mullan M, Paris D (2010) Alzheimer's $\beta$-amyloid peptide blocks vascular endothelial growth factor mediated signaling via direct interaction with VEGFR-2. J Neurochem 112:66-76.

Peng S, Wuu J, Mufson EJ, Fahnestock M (2004) Increased proNGF levels in subjects with mild cognitive impairment and mild Alzheimer disease. J Neuropathol Exp Neurol 63:641-649.

Perry G, Smith MA, McCann CE, Siedlak SL, Jones PK, Friedland RP (1998) Cerebrovascular muscle atrophy is a feature of Alzheimer's disease. Brain Res 791:63-66.

Petrovitch H, White LR, Izmirilian G, Ross GW, Havlik RJ, Markesbery W, Nelson J, Davis DG, Hardman J, Foley DJ, Launer LJ (2000) Midlife blood pressure and neuritic plaques, neurofibrillary tangles, and brain weight at death: the HAAS, Honolulu-Asia Aging Study. Neurobiol Aging 21:57-62.

Plate KH, Risau W (1995) Angiogenesis in malignant gliomas. Glia 15: 339-347.

Roe CM, Fitzpatrick AL, Xiong C, Sieh W, Kuller L, Miller JP, Williams MM, Kopan R, Behrens MI, Morris JC (2010) Cancer linked to Alzheimer disease but not vascular dementia. Neurology 74:106-112.

Schultheiss C, Blechert B, Gaertner FC, Drecoll E, Mueller J, Weber GF, Drzezga A, Essler M (2006) In vivo characterization of endothelial cell activation in a transgenic mouse model of Alzheimer's disease. Angiogenesis 9:59-65.

Selkoe DJ (2008) Soluble oligomers of the amyloid beta-protein impair synaptic plasticity and behavior. Behav Brain Res 192:10613.

Siedlak SL, Cras P, Kawai M, Richey P, Perry G (1991) Basic fibroblast growth factor binding is a marker for extracellular neurofibrillary tangles in Alzheimer disease. J Histochem Cytochem 39:899-904.

Skoog I, Lernfelt B, Landahl S, Palmertz B, Andreasson LA, Nilsson L, Persson G, Odén A, Svanborg A (1996) 15-year longitudinal study of blood pressure and dementia. Lancet 347:1141-1145.

Snowdon DA, Greiner LH, Mortimer JA, Riley KP, Greiner PA, Markesbery WR (1997) Brain infarction and the clinical expression of Alzheimer disease. The Nun Study. JAMA 277:813-817.

Solito R, Corti F, Fossati S, Mezhericher E, Donnini S, Ghiso J, Giachetti A, Rostagno A, Ziche M (2009) Dutch and Arctic mutant peptides of beta amyloid(1-40) differentially affect the FGF-2 pathway in brain endothelium. Exp Cell Res 315:385-395.

Spuch C, Antequera D, Portero A, Orive G, Hernández RM, Molina JA, Bermejo-Pareja F, Pedraz JL, Carro E (2010) The effect of encapsulated VEGF-secreting cells on brain amyloid load and behavioral impairment in a mouse model of Alzheimer's disease. Biomaterials 31:5608-5618.

Suter OC, Sunthorn T, Kraftsik R, Straubel J, Darekar P, Khalili K, Miklossy J (2002) Cerebral hypoperfusion generates cortical watershed microinfarcts in Alzheimer disease. Stroke 33:1986-1992.

Takeuchi D, Sato N, Shimamura M, Kurinami H, Takeda S, Shinohara M, Suzuki S, Kojima M, Ogihara T, Morishita R (2008) Alleviation of Ab- 
induced cognitive impairment by ultrasound-mediated gene transfer of HGF in a mouse model. Gene Ther 15:561-571.

Tarkowski E, Issa R, Sjögren M, Wallin A, Blennow K, Tarkowski A, Kumar P (2002) Increased intrathecal levels of the angiogenic factors VEGF and TGF-beta in Alzheimer's disease and vascular dementia. Neurobiol Aging 23:237-243.

Thirumangalakudi L, Samany PG, Owoso A, Wiskar B, Grammas P (2006) Angiogenic proteins are expressed by brain blood vessels in Alzheimer's disease. J Alzheimers Dis 10:111-118.

Tirumalasetti F, Han L, Birkett DP (1991) The relationship between cancer and Alzheimer's disease. J Am Geriatr Soc 39:840.

Vagnucci AH Jr, Li WW (2003) Alzheimer's disease and angiogenesis. Lancet 361:605-608.

Wagemakers M, van der Wal GE, Cuberes R, Alvarez I, Andrés EM, Buxens J, Vela JM, Moorlag H, Mooij JJ, Molema G (2009) COX-2 inhibition combined with radiation reduces orthotopic glioma outgrowth by targeting the tumor vasculature. Transl Oncol 2:1-7.

Watson D, Castaño E, Kokjohn TA, Kuo YM, Lyubchenko Y, Pinsky D, Connolly ES Jr, Esh C, Luehrs DC, Stine WB, Rowse LM, Emmerling MR, Roher AE (2005) Physicochemical characteristics of soluble oligomeric Abeta and their pathologic role in Alzheimer's disease. Neurol Res $27: 869-881$.
Wu Z, Guo H, Chow N, Sallstrom J, Bell RD, Deane R, Brooks AI, Kanagala S, Rubio A, Sagare A, Liu D, Li F, Armstrong D, Gasiewicz T, Zidovetzki R, Song X, Hofman F, Zlokovic BV (2005) Role of the MEOX2 homeobox gene in neurovascular dysfunction in Alzheimer disease. Nat Med 11:959-965.

Yamada M, Sasaki H, Mimori Y, Kasagi F, Sudoh S, Ikeda J, Hosoda Y, Nakamura S, Kodama K (1999) Prevalence and risks of dementia in the Japanese population: RERF's adult health study Hiroshima subjects. Radiation Effects Research Foundation. J Am Geriatr Soc 47:189-195.

Yashin AI, Ukraintseva SV, Akushevich IV, Arbeev KG, Kulminski A, Akushevich L (2009) Trade-off between cancer and aging: What role do other diseases play? Evidence from experimental and human population studies. Mech Ageing Dev 130:98-104.

Zagzag D, Zhong H, Scalzitti JM, Laughner E, Simons JW, Semenza GL (2000) Expression of hypoxia-inducible factor lalpha in brain tumors: association with angiogenesis, invasion, and progression. Cancer $88: 2606-2618$.

Zlokovic BV (2005) Neurovascular mechanisms of Alzheimer's neurodegeneration. Trends Neurosci 28:202-208.

Zlokovic BV, Shinia Y, Holtzman D, Ghiso J, Frangione B (2000) Clearance of b-amyloid from brain: transport or metabolism? Nat Med 6:718-719. 